NBER WORKING PAPER SERIES

\title{
CHOOSING A HUMAN CAPITAL MEASURE: EDUCATIONAL ATTAINMENT GAPS AND RANKINGS
}

\author{
Barbara M. Fraumeni \\ Working Paper 21283 \\ http://www.nber.org/papers/w21283 \\ NATIONAL BUREAU OF ECONOMIC RESEARCH \\ 1050 Massachusetts Avenue \\ Cambridge, MA 02138 \\ June 2015
}

This paper was prepared for the New Directions in Human Capital Theory conference at the Birmingham Business School, Birmingham, England, June 26, 2015. The views expressed herein are those of the author and do not necessarily reflect the views of the National Bureau of Economic Research.

NBER working papers are circulated for discussion and comment purposes. They have not been peerreviewed or been subject to the review by the NBER Board of Directors that accompanies official NBER publications.

(C) 2015 by Barbara M. Fraumeni. All rights reserved. Short sections of text, not to exceed two paragraphs, may be quoted without explicit permission provided that full credit, including $\odot$ notice, is given to the source. 
Choosing a Human Capital Measure: Educational Attainment Gaps and Rankings

Barbara M. Fraumeni

NBER Working Paper No. 21283

June 2015

JEL No. E24,I25

\begin{abstract}
$\underline{\text { ABSTRACT }}$
According to the World Bank and the United Nations, human capital is the largest component of human wealth for most countries in the world. There is no question that human capital is critical to individual and society well-being and both present and future growth. This presentation draws upon an analysis of human capital measures for 18 countries, including the three most populous countries in the world: China, India, and the United States. This paper will focus on two human capital issues, which are considerations in choosing a human capital measure: the size of the educational attainment gap between those younger and older, and differences in rankings using alternative human capital measures.
\end{abstract}

In a number of countries, younger individuals (age 25-24) have a significantly higher educational attainmentlthan older individuals (aged 55-64). For these countries, expectations are that economic growth and『well-being will improve over the longer term. Lifetime income measures which explicitly includelthe expected future work history and income of all individuals in a country are preferred over otherlmeasures if these gaps matter.

The answer to the question: "What is the human capital ranking of countries?" depends upon the referencelmeasure. Six types of measures are considered: PISA test scores, PIAAC, Barro-Lee educationallattainment, Inclusive Wealth human capital, Jorgenson-Fraumeni lifetime income, and World Banklintangible capital. What explains the significant differences in the rankings? Is it important unmeasuredlattributes or country specific institutions and labor markets? Is it a failure of standard economic assumptions,[such as individuals being paid what they are worth, to predict labor market outcomes? It is critical[to answer these questions before choosing a human capital measure to predict economic growth and[well-being in general, and notably the impact of younger cohorts being more highly educated thanПolder cohorts.

Barbara M. Fraumeni

\&HQWDOB QYHHWWUIRU) IQDOFHIDQA( FRQRP IFV

770 Middle Road

Dresden, ME 04342

and NBER

Barbara_Fraumeni@hotmail.com 
Choosing a Human Capital Measure: Educational Attainment Gaps and Rankings Barbara M. Fraumeni

According to the World Bank and the United Nations, human capital is the largest component of human wealth for most countries in the world (World Bank, 2006, 2011 and UNU-IHDP and UNEP, 2014). There is no question that human capital is critical to individual and society wellbeing and both present and future growth. Acknowledging the importance of human capital, the question remains as to how we should measure human capital? This paper will focus on two human capital issues, which are considerations in choosing a human capital measure: the size of the educational attainment gap between those younger and older and differences in rankings using alternative human capital measures. It leaves open the question of why rankings differ for future research.

Human capital rankings are presented for 18 countries, including the three most populous countries in the world: China, India, and the United States, and for at most ten measures. The full list of countries include: Australia, Canada, China, Denmark, France, India, Israel, Italy, Japan, Netherlands, New Zealand, Norway, Poland, Romania, South Korea, Spain, the United Kingdom, and the United States. The ten possible measures include those for OECD's Programme for International Student Assessment (PISA) for science, reading and mathematics, OECD's Programme for International Assessment of Adult Competencies (PIAAC) for literacy, numeracy, and problem solving in tech-rich environments, Barro-Lee (B-L) average educational attainment, Inclusive Wealth Report (IWR) human capital per capita, Jorgenson-Fraumeni (J-F) per capita human capital and World Bank (WB) intangible capital. Of the ten measures, the WB measure is the only one which includes other components that are not measures of human capital. Ranking years vary, but are either for 2005 or 2006 with the exception of the three PIAAC measures as the first results from this program are available for 2011-12. Ages covered also vary, but are typically for ages 15 or 16 to 64 or 65, with the exception of PISA (age 15 in 2006 results), IWR (all ages) and WB (all ages). ${ }^{1}$ Significant variation exists in the country rankings.

The size of the educational attainment gap between those younger and older for the 18 country sample is examined in this paper as this gap is clearly indicative of whether changes are underway in country human capital. Human capital measures which predict continuing changes are clearly preferred.

This paper begins by summarizing the methodologies underlying each of the measures included in the rankings and gap analysis. A presentation and discussion of the country rankings is next, followed by a presentation and discussion of the educational attainment gaps. The conclusion summarizes and presents questions for future research.

\footnotetext{
${ }^{1}$ Exceptions to the year, age and measure covered for individual countries are noted in body of the paper.
} 


\section{Methodologies}

\section{OECD PISA and PIAAC}

PISA and PIAAC are two international OECD sponsored tests whose results can be used as measures of human capital. PISA assesses student knowledge and skills and PIAAC assesses adult skills and their utilization.

This paper focuses on results from the 2006 PISA as all of the other human capital measures, except for that from PIAAC, are from 2005 or 2006. In 2006, 57 countries and over 400 thousand students participated. Although in 2006, 2009, and 2012, at a minimum tests were offered in mathematics, science and reading, the 2006 PISA focused on science, the 2009 PISA focused on reading, and the 2012 PISA focused on mathematics. PISA testing also occurred in 2000 and 2003. In 2003 and 2012 tests were also offered in problem solving. In 2012 an optional test: financial literacy, was added. ${ }^{2}$

PIAAC, a new OECD adult testing program, includes problem-solving and reading components. Twenty-four countries initially participated, with an additional nine countries being added in 2014. About 166 thousand 16 to 65 year olds took this test in 2011-12. Results across countries and subnational entities varied widely, with the difference in the average score between the highest performing countries and the lowest performing countries amounting to more than five years of formal education. ${ }^{3}$

\section{$\underline{\text { Barro-Lee }^{4}}$}

A widely used human capital measure is Barro and Lee (2013a, 2013b) average (formal) educational attainment. The data set covers average educational attainment beginning at age 15, in five-year age increments, for the total population and females; data is available for every five years from 1950 to 2010, for 146 countries. Population numbers are also available in the data set for each associated educational attainment estimate. Benchmark data is collected from census and/or survey information and compiled by UNESCO, Eurostat, national statistic agencies, and other sources.

Barro-Lee uses a variety of techniques to fill in gaps in observations and educational attainment subcategories, and to avoid mis-estimation of average years of schooling.

To fill in missing observations (as benchmarks are not available for all five-year periods), they begin by calculating the distribution of educational attainment among four broad categories: no

\footnotetext{
${ }^{2} \operatorname{OECD}(1999,2003,2007$, undated)

${ }^{3}$ OECD (November 2013, 2013, undated)

${ }^{4}$ This Barro-Lee, Inclusive Wealth, and Jorgenson-Fraumeni methodology sections are largely taken without change from Fraumeni and Liu (2014).
} 
formal education $(h u)$, primary $(h p)$, secondary $(h s)$, and tertiary education $(h h)$. Primary and tertiary are further divided into complete and incomplete; secondary is further divided into lower secondary and upper secondary.

Most missing observations are filled in with backward or forward extrapolation with an appropriate time lag. There are 12 five-year age groups ( $a g)$, from $a g=1(15-19)$ to $a g=12$ (7074), plus one age group $a g=13$ ( 75 and over).

The forward extrapolation method assumes that the educational attainment distribution of an age group $a g$ at time $t$ is identical to that of the age distribution that was five years younger at time $t$ 5.

\section{EQUATION 1}

$\operatorname{hj}(\operatorname{ag}, t)=\operatorname{hj}(a g-1, t-5)$

for $j=u, p$, s, or $h$ and $a g=3$ (25-29) through $a g=11(65-69)$. As those younger than 25 are potentially still in school, a different methodology is employed.

Similarly, backward extrapolation assumes that the educational attainment distribution of an age group $a g$ at time $t$ is identical to the age distribution that was five years older at time $t+5$.

EQUATION 2

$h j(a g, t)=h j(a g+1, t+5)$

for $j=u, p$, s, or $h$ and $a g=3$ (25-29) through $a g=11$ (65-69).

The net effect of this methodology is to hold an individual's educational attainment constant from age 25 through 64 .

For older individuals, the probability of dying differs by educational attainment level.

Accordingly, for the three oldest age groups: $a g=11$ (65-69), $a g=12$ (70-74), and $a g=13$ (75 and older), survival probabilities are estimated by educational attainment level. Highly educated individuals live, on average, longer than their less educated peers; this correction is necessary to ensure accurate estimations of average educational attainment for older age groups. For all younger age groups ( $\mathrm{ag}=10$ and below), it is assumed that survival rates do not differ by educational attainment.

The process for creating subcategories of educational attainment (complete and incomplete for primary and higher education; lower and upper for secondary school) depends upon the age level.

For primary school, Barro-Lee use country and age-specific completion ratio profiles to estimate the subcategories for $a g=1$ (15-19) and $a g=2$ (20-24). For $a g=3$ (25-29), the primary school completion rate is set equal to the ratio of the number of individuals who completed primary school, but did not enter secondary school, to the number of individuals who entered primary 
school. Backward and forward extrapolation and other methods are used to fill in any missing observations for $a g=3$ (25-29) and above.

When there are missing observations, secondary-school enrollees for $a g=1$ (15-19) are assumed to be incompletely educated at the secondary level, and higher-school enrollees for $a g=2$ (20-24) are assumed to be incompletely educated at the higher level.

Other estimation problems arise because some countries do not report the proportion of the population who have no formal education, but do report on the proportion of the educated population who have achieved primary, secondary, or tertiary level of education. Alternatively, the proportion of the population with no formal education, or has achieved at most some level of primary education, is often reported as a single number. Barro-Lee uses illiteracy rate, primary enrollment ratio, and/or data from other census years to resolve such inconsistencies.

Finally, average number of years of schooling are estimated for those aged 15 and above, and separately for each of the 13 age categories. For those aged 15 and above:

$$
\begin{aligned}
& \text { EQUATION } 3 \\
& S(t)=\Sigma(\text { ag,t }) S(\text { ag, } t)
\end{aligned}
$$

where the summation is over all age groups, $l(a g, t)$ is the population share of the group aged $a g$ in the total population aged 15 and above, and $s(a g, t)$ is the average number of years of schooling for age group ag.

The average number of years of schooling by age group $a g$ is:

EQUATION 4

$S(a g, t)=\operatorname{Lhj}(a g, t) \operatorname{Dur}(j, a g, t)$

where the summation is over educational levels $j$ ( $p, s$ (incomplete, complete), $h$ (incomplete, complete)), $h j(a g, t)$ is the fraction of the group aged $a g$ with the educational level $j$, and Dur is the duration of school attendance in years.

\section{Inclusive Wealth}

The Inclusive Wealth (IW) human capital methodology follows that of Arrow, Dasgupta, et al. (2012a, 2012b) and Klenow and Rodríguez-Clare (2005). IWR 2014 country aggregates are estimated for 140 countries. The country aggregates, separated by gender, which enter into the calculation are: average formal education attainment, average wage, total number of employed, total adult population, and average expected remaining working years. 
The first methodology step is to estimate human capital per capita. Following Klenow and Rodríguez-Clare (2005), education is assumed to earn a market rate of interest, $\rho$, of 8.5 percent per annum. Human capital per person is:

\section{EQUATION 5}

$$
h=e^{(E d u * \rho)}
$$

where $E d u$ is the average number of years of educational attainment in a formal setting (from Barro-Lee). As expected with an exponential function, human capital per person rises at an increasing rate with increases in the average number of years of educational attainment. Note that the human capital of a person with eight years of education is estimated to be almost twice that of a person with no education.

As all adults have human capital, even if they do not work, $h$ is multiplied by the total number of adults in the country to determine total human capital. The number of adults in the country is defined as the number of individuals of age $(E d u+5)$. As Edu varies by country, the age of someone who is considered to be an adult varies significantly by country.

IW assumes that the labor market is sufficiently competitive such that the marginal productivity of human capital can be assumed to be equal to the real wage rate, $r$. The shadow price for a unit of human capital is then calculated as the real wage rate, $r$, discounted over the expected number of working years remaining, $T$, for the average adult:

$$
\begin{aligned}
& P_{K_{\text {Human }}}=\int_{t=0}^{T} r \cdot e^{-\delta \text { t }} d t
\end{aligned}
$$

where $\delta$, the discount rate, is set equal to 8.5 percent per annum. IW uses World Health Organization life tables and U.S. Census Bureau demographic data by country and gender to calculate the average expected remaining working years, $T$, across all individuals of working age. The real wage is computed as a country's average total wage bill divided by the total number of workers in the country, over the 1990 to 2010 time period. The expected number of working years remaining is estimated by contemporaneous (as opposed to expected future) age-gender participation and mortality rates. Labor market information, such as employment, wages, and labor force participation come from a variety of sources, including the International Labour Organization, the Conference Board, and the United Nations Statistics Division. 
Country total human capital depends on the average educational attainment, real wage rate, and adult population. Total human capital is divided by the total population, regardless of age, to determine country level per capita human capital: ${ }^{5}$

\section{EQUATION 7}

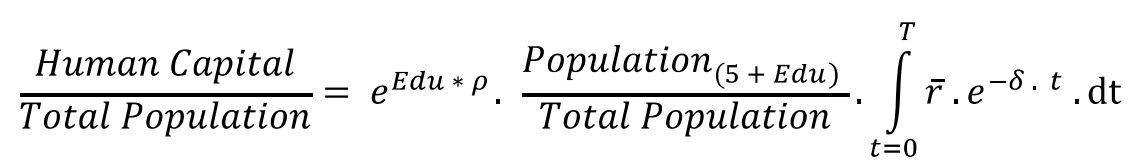

The first term on the right-hand side of the equation is the human capital per capita expression from equation 5; the third term on the right-hand side of the equation is the shadow price for a unit of human capital expression from equation 6 . The age composition of the population, entering through the second term on the right-hand side of the equation, clearly impacts the above human capital ratio. Population estimates are from the Population Division of the United Nations Department of Social and Economic Affairs.

\section{Jorgenson-Fraumeni}

The J-F lifetime income approach applies the neoclassical theory of investment (Jorgenson, 1967) to human capital. According to this theory, the price of capital goods depends upon the discounted value of all future capital services derived from the investments. On a per capita basis, this means that the value of the human capital of an individual can be determined from that person's discounted lifetime income.

The J-F methodology (1989, 1992a, 1992b) is modified, most notably by Liu (2011), to reduce estimation difficulty and time requirements; to deal with data availability constraints; and to reflect country-specific conditions. J-F human capital accounts have been constructed for 20 countries. ${ }^{6}$ Almost all country studies have estimated only market lifetime income because of the additional assumptions, time, and data needed to include nonmarket lifetime income as part of human capital.

\footnotetext{
${ }^{5}$ In this equation, "r" should not have a bar over it.

${ }^{6}$ The countries include: Argentina, Australia, Canada, China, Denmark, France, India, Israel, Italy, Japan, the Netherlands, New Zealand, Norway, Poland, Rumania, South Korea, Spain, Sweden, United Kingdom, and the United States. See Argentina (Coremberg, 2010), Australia (Wei, 2007, 2008a, 2008b), Canada (Gu and Wong, 2009), China (Li, 2010b, 2011, 2012, 2014 and Li et al., 2009a and 2013), India (Gundimeda, Sanyal, Sinha, and Sukhdev, 2007), New Zealand (Le, Gibson, and Oxley, 2005), Norway (Liu and Greaker, 2009), Sweden (Ahlroth and Bjorkland, 1997), the United States (Christian, 2009, 2010, 2014) and Mira and Liu (2010) and Liu for the OECD consortium (2011). O’Mahony and Stevens (2004) applied J-F methodology to evaluate government provided education in Great Britain. As the references above indicate, for several countries, OECD human capital project estimates exist as well as estimates constructed during the course of other research projects.
} 
The following sets of data for a J-F simplified approach (Fraumeni, 2008a) as implemented by Liu (2011) are required, except as noted for ages 15 through 64 and gender: 1) working age population; 2) survival rates; 3) school enrollment rates for ages 15 through 29 by single year, ages 30-34 and 35-39 by five year categories, and 40 and above; 3) educational attainment; and 4) annual earnings.

The simplified approach identifies three life stages. ${ }^{7}$ The characteristics of these stages are dictated by typical life stages and data availability. In the equations that follow, the following notation is used:

mi: Expected lifetime market income per capita, discounted to the present

$R$ : The adjustment factor applied to lifetime income

$=(1+$ real rate of growth on labor income $) /(1+$ real discount rate $)$

sr: Survival rate

senr: Formal school enrollment rate and

ymi: Yearly market income per capita.

for subscripts:

a: Age

$e$ : Highest level of education completed

enr: Formal education enrollment level

older: Equal to $a+1$

$s:$ Gender, and

school: Equal to $e+1$.

The nominal market value life stage equations are as follows:

\section{Stage 1: Work and school, ages 15 through 40 when an individual could be enrolled in school}

For these ages, individuals can attend school and perform market work. It is assumed that dropouts do not later continue their education, that no grades are skipped or repeated, and that once enrolled, a student finishes that year of education. Market hours are valued at the average wage or income paid for the corresponding gender, age, and highest education level completed category. In stage 1, individuals earn income in the current year, and if they survive for another year, can earn the lifetime income of someone who is a year older than the individual's current age. The individual's future lifetime income is dependent upon whether they are enrolled in school or not. Finally, as is true for both stage 1 and 2, the income sum is adjusted by $R$, the

\footnotetext{
${ }^{7}$ Jorgenson-Fraumeni estimated nonmarket lifetime income for two more stages to include those too young to be doing market work. Their first stage (ages 0 through 4) is a no market work, no school stage. Their second stage (ages 5 through 15) is a no market work, school stage.
} 
factor reflecting a future real rate of growth in labor income and discounts the income sum back to the present.

$$
\begin{aligned}
& \text { EQUATION } 8 \\
& \begin{aligned}
\text { mi }(s, a, e) & =y m i(s, a, e)+[\operatorname{senr}(s, a, e n r) * \operatorname{sr}(s, \text { older }) * m i(s, o l d e r, s c h o o l) \\
& +(1-\operatorname{sen} r(s, a, e n r)) * \operatorname{sr}(s, \text { older }) * m i(s, \text { older }, e)] * R
\end{aligned}
\end{aligned}
$$

\section{Stage 2: Work only, ages 41 through 64 when it is assumed that an individual is not enrolled in school}

For these ages, it is assumed that no one is enrolled in school, as insufficient data existed on students above the age of 40. Human capital therefore depends only on a person's expected future market income and whether the individual survives for another year.

$$
\begin{aligned}
& \text { EQUATION } 9 \\
& m i(s, a, e)=y m i(s, a, e)+s r(s, \text { older }) * m i(s, \text { older }, e) * R
\end{aligned}
$$

\section{Stage 3: Retirement, age 65 and over}

When only market lifetime income is counted in a J-F computation, the human capital of retired persons is zero. Because of data constraints, it is assumed that everyone aged 65 or older is retired.

$$
\begin{aligned}
& \text { EQUATION } 10 \\
& m i(s, a, e)=0 .
\end{aligned}
$$

Calculations are done in a backwards recursive manner, starting from the oldest age group and continuing to the youngest age group. For example, for a particular year - say, 2000 - the computations start by setting the lifetime income of someone who is 65 equal to zero. If lifetime incomes are being computed by single year of age, the next calculation would be for a 64-yearold: Because the lifetime income of a 65-year-old is zero, the 64-year-old's lifetime income is equal to the income that person earns in 2000. All but the first term in equation 9 drop out.

For someone who is 63 in 2000, there are two possible components to their lifetime income: income earned in the current year and, if they survive for another year, lifetime income of someone who is 64 in 2000. The 63-year-old's future lifetime income is adjusted for a one-year change in the real wage rate and discounted for the one year before the 63-year-old in 2001 receives the thusly adjusted income of a 64-year-old in 2000.

The sequence continues backwards, with each step reducing the age of the person for which the computation is made by one year. The future lifetime income of a 63-year-old, should they live until age 64, has already been adjusted for a one-year change in the real wage rate and 
discounted. Accordingly, for a 62-year-old, there is only a one-year real wage rate and discounting adjustment appearing in the equation.

It is assumed that the relative wage rates by educational attainment levels are determined by contemporaneous relative wage rates, survival rates, and enrollment rates. For example, the information regarding the probability that someone who is 20 in 2000 will enroll in school and survive until he is 21 in 2001, as well as the wage the person will earn in 2001 compared to someone who does not continue in school in 2000, is predicted by the information about someone of the same gender who is 21 in 2000, perhaps with one more year of school completed in $2000 .^{8}$

Total nominal human capital is constructed by multiplying each stage's market income per capita by the population of the corresponding ages, which is then summed to determine total human capital across ages 15 to 64 . For all stages except for stage 1, which involves possible school enrollment, a total stage population suffices. For stage 1, population by single year of age or by five-year categories for some ages is required.

Two different types of volume indices are constructed. Divisia (Tornqvist) temporal volume indices are constructed with a weighted growth rate to compare stocks of human capital over time. The weights are nominal human capital and the growth rates are population growth rates for the corresponding age/educational category. Spatial indices are derived by dividing nominal human capital by purchasing power parities (PPPs) to compare human capital in real terms between different countries at one point in time. ${ }^{9}$

\section{World Bank}

The World Bank (2006, 2011) uses a residual approach to estimating human capital for over 120 countries. Total wealth, $w_{t}$, for the years 1995, 2000 and 2005 is measured as the net present value of an assumed future consumption stream, $C(s)$. The methodology is based on the Ramsey formula:

$$
\begin{aligned}
& \text { EQUATION } 11 \\
& w_{t}=\int_{t}^{\infty} C(s) \cdot e^{-r(s-t)} d s,
\end{aligned}
$$

where $r$ is the social rate of return. Using a net present value approach to estimate total wealth requires assumptions about the time horizon and the discount rate. The World Bank chooses 25 years as the time horizon as it roughly corresponds to one generation. It chooses a social discount

\footnotetext{
${ }^{8}$ Because of the rapidly changing school enrollment rates in China, the probability that a Chinese student will enroll in school when they are one year older was allowed to increase. See, for example, Li (2012).

${ }^{9}$ Liu (2011). 
rate rather than a private rate as governments would use a social discount rate to allocate resources across generations. The social discount rate is set at 4 percent, which is at the upper range of estimates it reviewed for industrialized countries. The same rate is used for all countries to facilitate comparisons across countries.

\section{EQUATION 12}

$$
r=\rho+\eta \cdot \dot{C} / C
$$

The pure rate of time preference $\rho$ is assumed to be 1.5 percent, the elasticity of utility with respect to consumption $\eta$ is assumed to be 1 and consumption growth $\dot{C}$ / $C$ is constant.

Intangible capital is equal to total wealth minus produced and natural capital. Intangible capital is an aggregate which includes human capital, the infrastructure of the country, social capital, and the returns from net foreign financial assets. Net foreign financial assets are included because debt interest obligations will affect the level of consumption.

The value of produced capital stocks is estimated with the perpetual inventory method. Produced capital includes both structures and equipment. Natural capital is valued by taking the present value of resource rents. Natural capital includes nonrenewable resources,cropland, pastureland, forested areas, and protected areas.

\section{Human Capital Measure Rankings}

If the six major types of human capital measures: PISA (with three subcomponents), PIAAC (with three subcomponents), Barro-Lee, Inclusive Wealth, Jorgenson-Fraumeni, and World Bank, all gave rise to approximately the same human capital country rankings, the focus would be on the information content of the different measures as reflected in the number of countries covered. Information content and the number of countries covered are generally inversely related, as normally it is data, time and resources needed to construct constraints that reduce the number of countries included in any measure. Analysts, researchers and policy-makers could choose between measures that cover a large number of countries, such as the Barro-Lee, Inclusive Wealth or World Bank measures, a significant number of countries, such as the PISA or PIAAC measures, or a limited number of countries, such as Jorgenson-Fraumeni, understanding the loss of greater detailed information. Unfortunately, the ten different measures clearly do not give rise to anything close to the same rankings as the following table illustrates. ${ }^{10}$

10 The PISA rankings are from OECD 2007. The science rankings are included in Table 2, p. 22; the reading rankings in Table 4, p. 47; and the mathematics rankings from Table 5, p. 53. The PIAAC rankings are from OECD, November 2013. The literacy scores are from Figure 2.4, p. 74; the numeracy scores are available from Figure 2.8, p. 84, and the problem solving in a tech-rich environment scores are available from Figure 2.10a. The details behind 
each of the PIAAC figures are available in an excel spreadsheet, the location of which is listed at the bottom of the figures in the PIAAC November 2013 text. Barro-Lee rankings are calculated from the Barro-Lee estimates (Barro and Lee, April 9, 2013). As a basis for the rankings, Inclusive Wealth Report (IWR) (2014) estimates in national currencies are divided by Purchasing Power Parities (PPPs) for private consumption and calculated in U.S. dollar equivalents. Jorgenson-Fraumeni (J-F) rankings were calculated for all countries except for China, India and Japan from spreadsheets underlying Liu (2011). For China, rankings data were obtained from spreadsheets underlying Li 2013b. For India, rankings data were obtained from Gundimeda, Sanyal, Sinha, and Sukhdev 2007. For Japan: rankings data were obtained directly from Gang Liu. As a basis for the rankings, J-F estimates in national currencies are divided by PPPs for private consumption and calculated in U.S. dollar equivalents. World Bank intangible capital per capita rankings are calculated from Table C-1, pp. 174-181 of World Bank 2011. World Bank data is the source for the PPPs and Gross Domestic Product in national currencies and UD dollars used in the creation of the IWR and J-F ranking estimates. The PPPs are the same as the PPPs used by Liu (2011). 


\begin{tabular}{|c|c|c|c|c|c|c|}
\hline $\begin{array}{l}\text { Table 1: } \\
\text { Country } \\
\text { Rankings }\end{array}$ & $\begin{array}{c}\text { PISA } \\
\text { Science, } \\
\text { Reading, } \\
\text { Math } \\
2006\end{array}$ & $\begin{array}{c}\text { PIAAC } \\
\text { Literacy, } \\
\text { Numeracy, } \\
\text { Problem- } \\
\text { solving in } \\
\text { tech-rich } \\
\text { environments } \\
2011-2\end{array}$ & $\begin{array}{c}\text { Barro-Lee } \\
\text { Average Ed } \\
\text { Attainment } \\
2005\end{array}$ & $\begin{array}{l}\text { Inclusive } \\
\text { Wealth } \\
\text { Report } \\
\text { per } \\
\text { Capita } \\
2005^{1}\end{array}$ & $\begin{array}{c}\text { Jorgenson- } \\
\text { Fraumeni } \\
\text { Human } \\
\text { Capital } \\
\text { per Capita } \\
2^{2006^{2}}\end{array}$ & $\begin{array}{c}\text { World } \\
\text { Bank } \\
\text { Intangible } \\
\text { Capital } \\
\text { per Capita } \\
2005\end{array}$ \\
\hline AGES & 15 & $16-65$ & $15-64$ & All Ages & $15-64$ & All Ages \\
\hline Australia & $4,4,6$ & $3,5,4$ & 7 & 9 & 9 & 10 \\
\hline Canada & $1,2,3$ & $5,6,5$ & 3 & 5 & 4 & 7 \\
\hline China & & & 17 & 18 & 18 & 17 \\
\hline Denmark & $9,9,7$ & $8,3,3$ & 14 & 7 & 8 & 2 \\
\hline France & $10,10,8$ & $11,10,-$ & 11 & 4 & 7 & 5 \\
\hline India & & & 18 & 17 & 17 & 18 \\
\hline Israel & $15,14,15$ & & 8 & 11 & 13 & 13 \\
\hline Italy & $14,12,14$ & $13,12,-$ & 12 & 12 & 14 & 8 \\
\hline Japan & $2,7,4$ & $1,1,6$ & 6 & 10 & 6 & 9 \\
\hline Netherlands & $5,6,2$ & $2,2,1$ & 9 & 6 & 10 & 6 \\
\hline New Zealand & $3,3,5$ & & 2 & 13 & 12 & 12 \\
\hline Norway & $13,11,11$ & $4,3,2$ & 4 & 2 & 3 & 4 \\
\hline Poland & $8,5,10$ & $10,9,10$ & 15 & 15 & 15 & 15 \\
\hline Romania & & & 10 & 16 & 16 & 16 \\
\hline South Korea & $6,1,1$ & $5,7,9$ & 5 & 14 & 5 & 14 \\
\hline Spain & $12,13,12$ & $12,13,-$ & 13 & 8 & 11 & 11 \\
\hline $\begin{array}{l}\text { United } \\
\text { Kingdom }\end{array}$ & $7,8,9$ & $7,8,6$ & 16 & 3 & 2 & 3 \\
\hline $\begin{array}{l}\text { United } \\
\text { States }\end{array}$ & $11,-, 13$ & $9,11,8$ & 1 & 1 & 1 & 1 \\
\hline
\end{tabular}

1. The Inclusive Wealth Report numerator human capital is for the population that is old enough to have obtained the average level of education for the country while the population in the denominator is for the country as a whole.

2. The J-F figures for Australia and India are for 2001; those for Denmark are for 2002. The ages covered for China include ages 16 through 55 for females and 16 through 59 for males. The ages covered for India include ages 15 through 60 . 
In this table, the three types of test for PISA are listed in the same column; the three types of tests for PIAAC are listed in the same column. In both cases, the rankings are listed in the same order as the testing types are listed in the heading. As is true for any column, if there are no results for any country, the corresponding row and column is blank. However, if some, but not all, of the PISA or PIAAC tests are not taken by residents of a particular country, a "_. appears instead of a numerical entry. For example, residents of the United States took the science and mathematics test, but not the reading test. Accordingly, a “-“ appears as the middle entry in the U.S.- PISA column. Note that if standard errors are considered, the PISA and PIAAC rankings might differ.

Country rankings sometimes differ substantially across or within the PISA and PIAAC test rankings. Instances when PISA test rankings differ by at least five places occur for Japan, Poland, and South Korea. Instances when PIAAC test rankings differ by at least five places occur for Denmark and Japan. Instances when PISA rankings differ from PIAAC rankings by at least five places (from the lowest PISA or PIAAC test ranking to the highest PIAAC or PISA test ranking) occur for Canada, the Netherlands, Norway, South Korea, and the United States. Creating a combined ranking for PISA and PIAAC separately or across PISA and PIAAC would inevitably be the result of arbitrary weighting, presumably with equal weights.

Country rankings sometimes differ substantially across the four other types of human capital rankings. Instances when the rankings differ by at least five places occur for Denmark, France, Israel, Italy, New Zealand, Romania, South Korea, Spain, and the United Kingdom.

More importantly, country rankings sometimes differ substantially across the six types of human capital measures. The difference between the lowest PISA or PIAAC test ranking and the highest ranking among the other four types of measures is at least five places for all countries whose residents took either the PISA or the PIAAC test. Of the three countries whose residents did not take either the PISA or PIAAC tests (China, India, and Romania), there exists a difference of at least five places only for Romania. Ranking differences between the lowest PISA or PIAAC test ranking and the highest ranking among the other four types of measures are at least 10 for six countries: Denmark, New Zealand, Norway, South Korea, the United Kingdom, and the United States.

As the long list of substantial differences in the rankings illustrate, there is no question that which human capital measure is chosen can significantly influence the rankings.

\section{Jorgenson-Fraumeni Compared to Barro-Lee Measures}

One of the major differences between Jorgenson-Fraumeni lifetime income human capital measures and Barro-Lee educational attainment human capital measures is the extent to which differences in educational attainment between the young and the old is reflected in the measures. The average educational attainment of those younger (age 25-34) is sometimes significantly higher than the educational attainment of those older (ages 55-64), according to the Barro-Lee 
data set. When these differences, or "gaps" in educational attainment occur, the educational attainment of those younger is more indicative of the future growth prospects of a country than the educational attainment of those older. Ceteris paribus, a human capital measure, such as J-F, which incorporate the contribution of individuals to present and future growth over their lifetime are preferred to other measures.

In table 2, the J-F estimates for human capital per capita shown in the figure below are sorted by level categories. The appropriate sorting seems evident from the figure. ${ }^{11}$

\section{Figure 1:}

International Comparison of J-F Human Capital per Capita, Individuals Aged 15-64, 2006

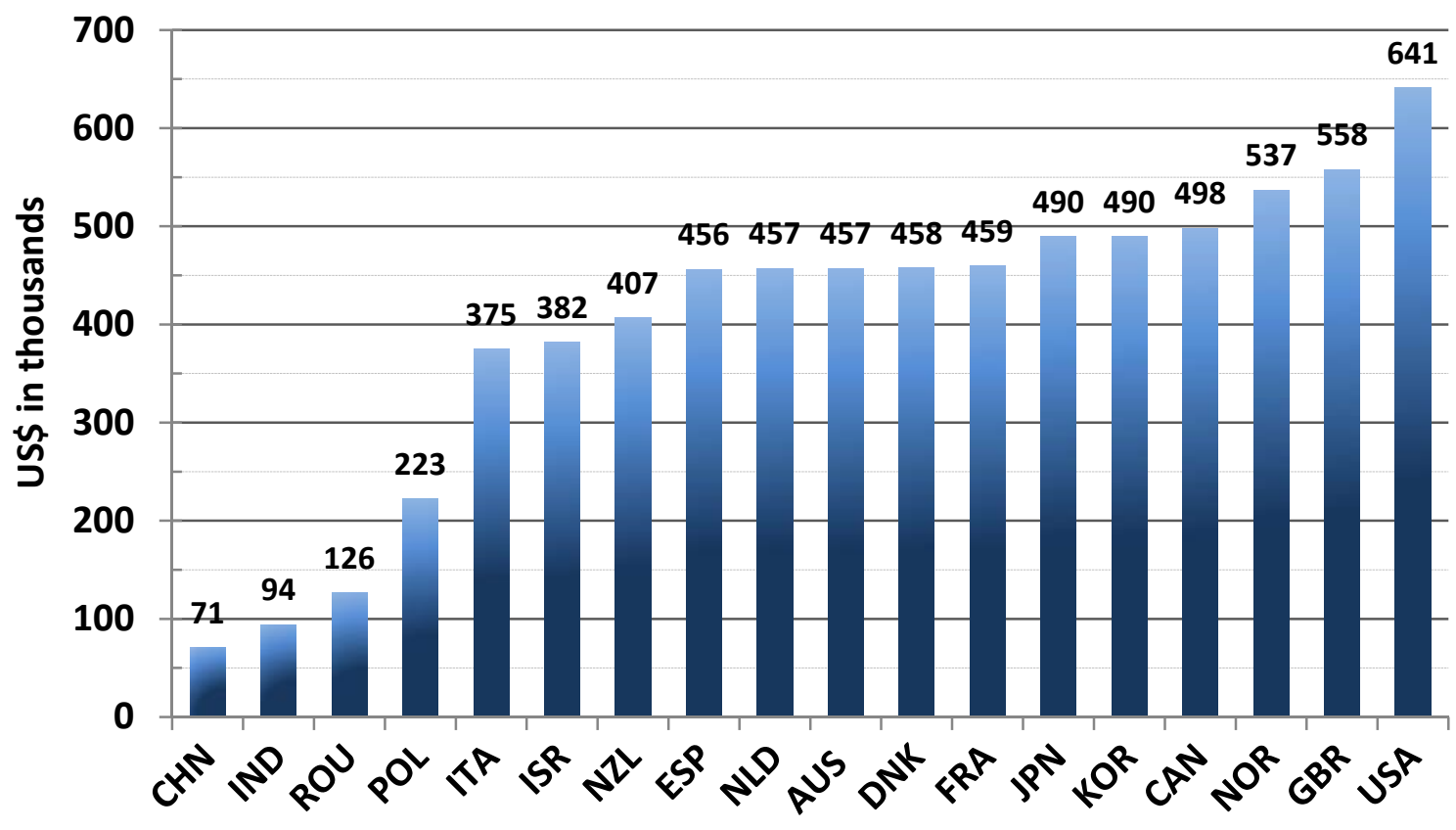

See table 1 footnotes.

\footnotetext{
${ }^{11}$ In some figures, the abbreviation "GBR" appears, which stands for Great Britain. Liu (2011) used this abbreviation. In fact, all of the results in Liu which are shown in this paper are for the United Kingdom. The United Kingdom includes Northern Ireland; Great Britain does not.
} 
Table 2: Ranking of Countries by J-F per Capita Lifetime Income

\begin{tabular}{|l|l|}
\hline Rank & Country \\
\hline Low & China, India, Poland, and Rumania \\
\hline Lower Middle & Israel, Italy, and New Zealand \\
\hline Upper Middle & Australia, Denmark, France, the Netherlands, and Spain \\
\hline Lower High & Canada, Japan and South Korea. \\
\hline Upper High & United Kingdom, Norway, and the United States \\
\hline
\end{tabular}

The next figure ranks countries by their Barro-Lee educational attainment. It illustrates one example of how different human capital rankings can be depending on the measure used. Differences are quite noticeable for countries in the low category, but they also are quite marked for some other countries, such as Israel, Italy, and New Zealand. The United Kingdom's average educational attainment is quite low, but its J-F lifetime human capital per capita is in the upper high category.

Figure 3 takes a look at the Barro-Lee average educational attainment for those aged 25-34 versus those aged 55-64 (the "gap”), as well as compares these estimates with the Barro-Lee average educational for those aged 15-64. Figure 4 shows the gap horizontally, with the average educational attainment across all 18 countries shown with a vertical line. This vertical line placement is mainly due to the large populations in China and India with low educational attainments. There is almost no gap for the Australia, Norway, Romania, and the United States; in fact in Denmark and Norway the younger group is on average less educated than the older group. It is well known that incomes, even by education categories, differ relatively little in these Scandinavian countries - perhaps due to taxation. In the United States, by contrast, there are very substantial returns to higher education, yet the educational attainment gap is very small. Gaps are large for either emerging or developing countries, such as China, India, and South Korea, as well as for highly developed countries, such as France, Italy, Japan, Spain, and the United Kingdom.

Table 3 cross classifies the 18 countries by the size of the Barro-Lee educational attainment gap and the level of J-F human capital per capita and Figure 5 shows the same information in a quadrant format. In Figure 5, the country markers are colored according to the quadrant in which they appear. The intersection of the gap axis and the human capital per capita axis occurs at a 1.25 years gap in educational attainment between the younger and the older individuals and a 


\section{Figure 2:}

For individuals aged 15 to 64, Barro-Lee average educational attainment 2005 compared with J-F human capital per capita 2006

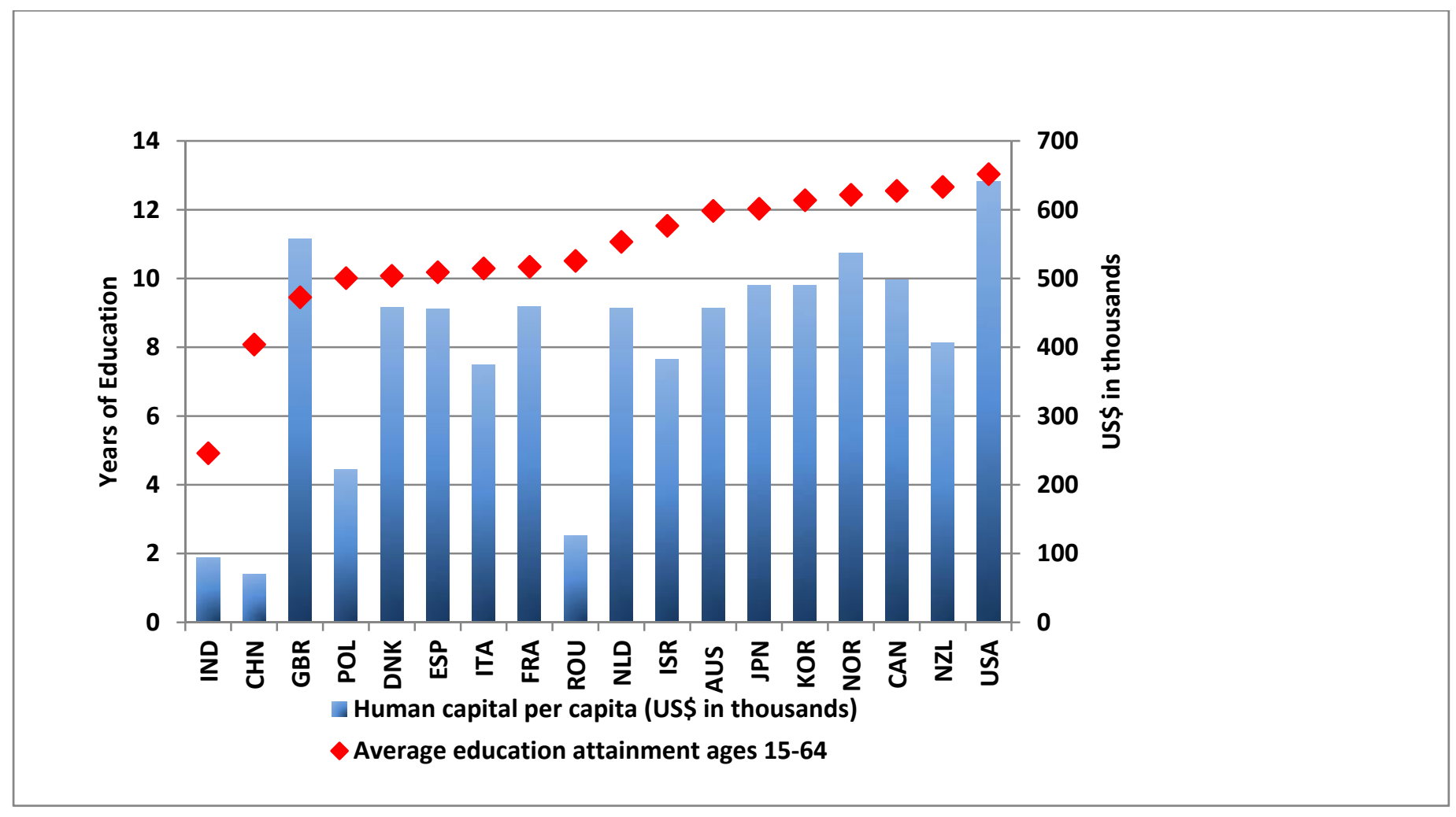

See table 1 footnotes.

US\$435 thousand lifetime income per capita. In both cases, these values are approximately at the mid-point of their categories. As expected, China and India have a large Barro-Lee educational attainment gap even though their level of J-F human capital per capita is very low. In the future, it is expected that average J-F human capital per capita of China and India will rise; however, it probably will take many years before either of them reaches a lower middle level. ${ }^{12}$ The two former Soviet Union countries: Poland and Romania, are in the small gap and low per capita human capital category. This may reflect the relative scarcity of economic institutions and their weakness in actual and expected returns to higher education. The high per capita income countries are all highly developed countries, with the exception of South Korea. Further research is needed to explain why educational attainment gaps differ for these countries.

\footnotetext{
${ }^{12}$ According to the estimates in table 5.2.1 of Li (2014), the quantity (volume) of J-F human capital per capita has been growing at an average rate of $11 \%$ s from 1998-2010. If this pace of growth continues and Italy's human capital per capita remains constant at its level in 2006, China would be categorized in the lower middle category in 2022.
} 
Figure 3: 2005 Educational Attainment Comparisons, Ages 25-34 vs. Ages 55-64

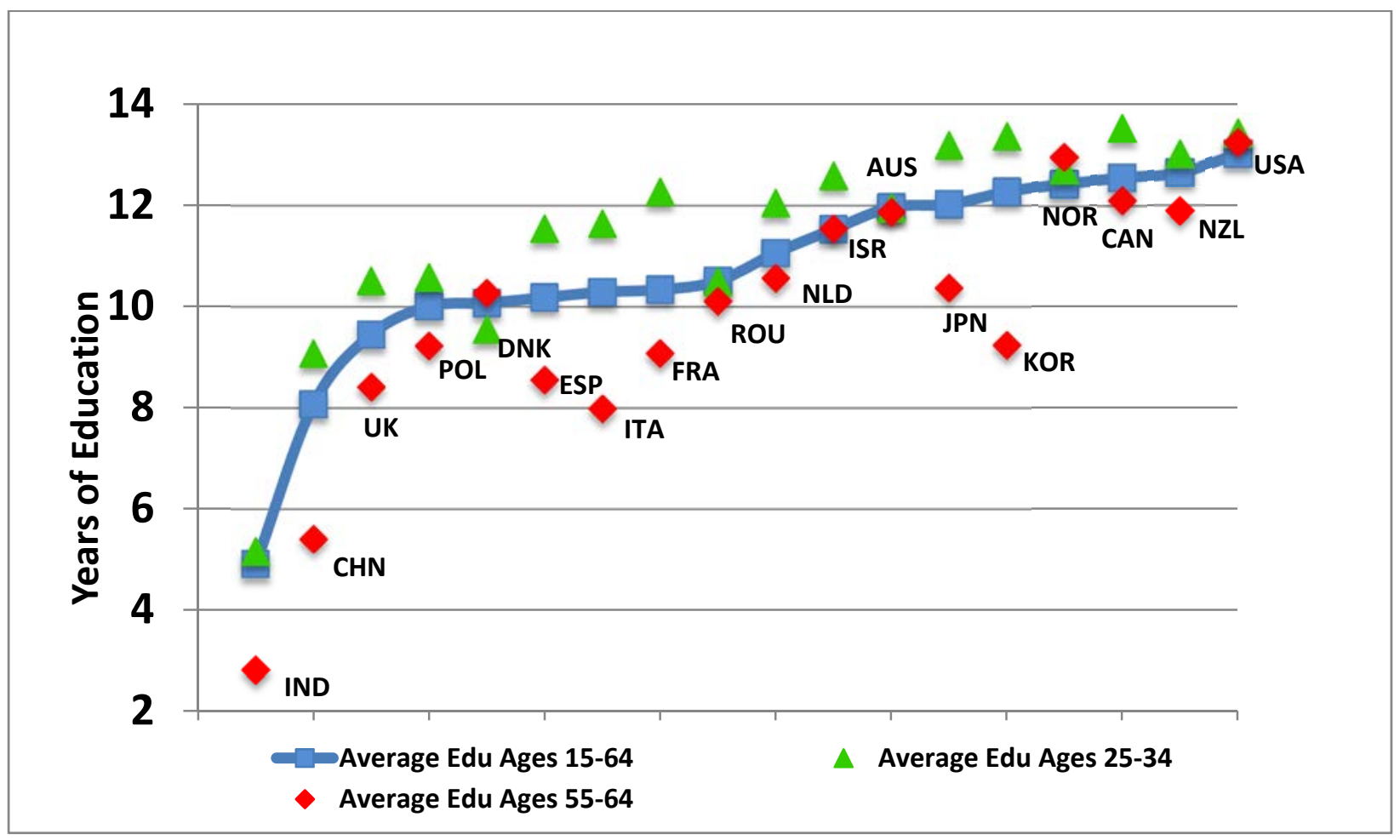

There is a significant clustering of countries around the gap axis in Figure 5. In the lower two quadrants, it is easy to see that China, India, Poland, and Romania are outliers, as their J-F income per capita is at least US $\$ 150$ thousand below that of other countries. In the upper two quadrants Norway, the United Kingdom, and the United States could also be classified as outliers, but this is less clear, even though their J-F income per capita is at a least about US\$ 40 thousand higher than that of other countries.

\section{Conclusion}

Arguably, human capital is more important to a country's present and future prospects than any other commonly measured productive input, e.g., labor, physical capital or natural capital. Yet as this paper demonstrates, country human capital rankings can differ significantly depending upon what measure is chosen. Clearly, educational attainment and the knowledge, skills, and problem solving abilities of adults should matter. Since there is not anything approaching a oneto-one correspondence between test results and other measures of human capital, what is missing? Are there individual characteristics which are important in the work place not captured by these tests? Is it labor market conditions and institutions which explain ranking variations 
among countries? Are there assumptions in the models underlying the IWR, J-F and World Bank methodologies which are unrealistic? For example, as an approximation to reality, is it reasonable to assume that are workers paid their relative marginal products? The answers to these and other questions can only be answered with a closer examination of the situation in individual countries. The answers may differ by country, yet it is important that at most a couple of human capital measures be chosen to help researchers, policy-makers, and government officials understand countries' human capital relative position. 
Figure 4: 2005 Educational Attainment Comparisons, Ages 25-34 vs. Ages 55-64

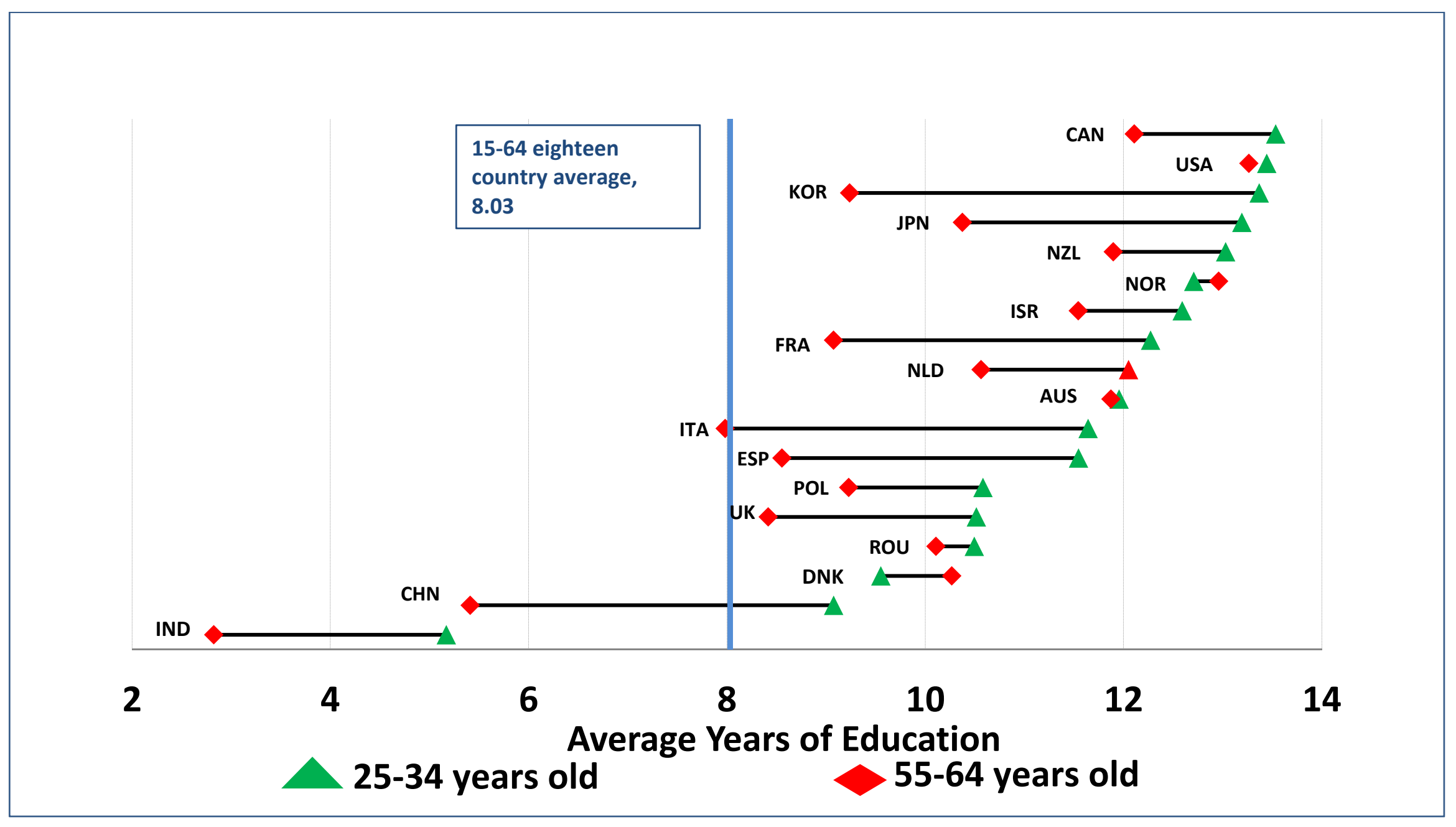


Table 3: Cross-classification of Barro-Lee Educational Attainment Gap and J-F Human Capital per Capita Categories

\begin{tabular}{|c|c|c|c|c|}
\hline & \multicolumn{3}{|c|}{$\begin{array}{l}\text { Level of Human Capital per } \\
\text { Capita }\end{array}$} \\
\hline & & LOW & MEDIUM & HIGH \\
\hline \multirow{3}{*}{$\begin{array}{l}\text { Size of } \\
\text { Educational } \\
\text { Attainment Gap }\end{array}$} & SMALL & ROU & $\begin{array}{l}\text { AUS } \\
\text { DNK }\end{array}$ & $\begin{array}{l}\text { NOR } \\
\text { USA }\end{array}$ \\
\hline & MEDIUM & POL & $\begin{array}{l}\text { NLD } \\
\text { ISR } \\
\text { NZL }\end{array}$ & CAN \\
\hline & LARGE & $\begin{array}{l}\text { CHN } \\
\text { IND }\end{array}$ & $\begin{array}{l}\text { ESP } \\
\text { FRA } \\
\text { ITA }\end{array}$ & $\begin{array}{l}\text { KOR } \\
\text { JPN } \\
\text { UK }\end{array}$ \\
\hline
\end{tabular}


Figure 5:

Cross-classification of Barro-Lee Educational Attainment Gap and J-F Human Capital per Capita Categories

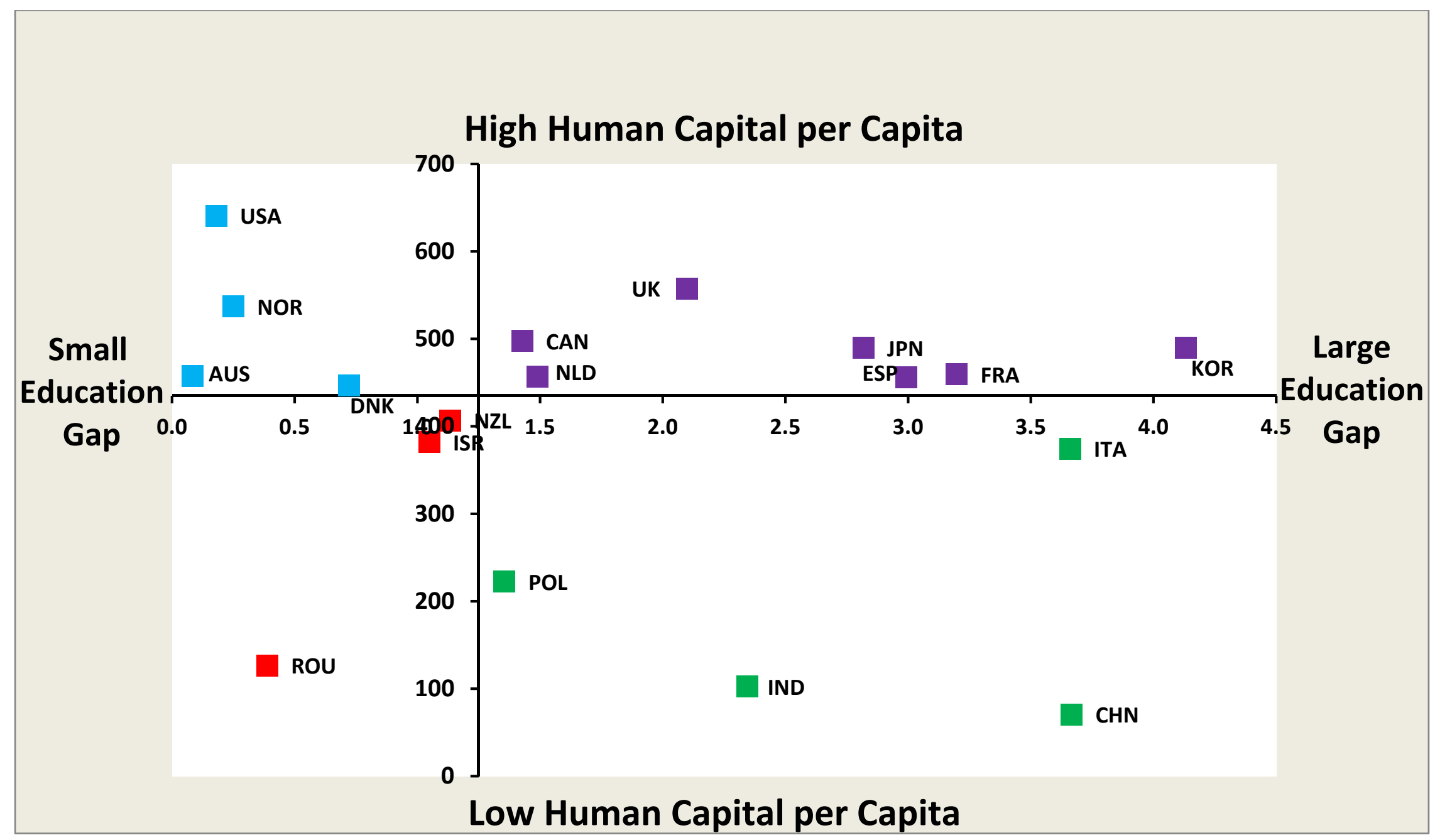




\section{Bibliography}

Ahlroth, S. A. and A. F. Bjorklund, “The Output of the Swedish Education Sector," Review of Income and Wealth Volume 43, Number 1, pp.89-104, 1997.

Barro, R. \& J. Lee, “A New Data Set of Educational Attainment in the World, 19502010,” Journal of Development Economics. 104(C). p. 184-198, 2013 a.

Barro, R. \& J. Lee, Barro-Lee Educational Attainment Data Set. Last updated April 9, 2013. Retrieved October 2013 from http://www.barrolee.com/ , 2013b.

Christian, M. S., “Human Capital Accounting in the United States: 1994 to 2006,” paper presented at the Bureau of Economic Analysis, December 14, 2009.

— , "Human Capital Accounting in the United States: 1994 to 2006," Survey of Current Business, 87(6), pp. 78-83, 2010.

— , "Human Capital Accounting in the United States: Context, Measurement, and Application,” in D. W. Jorgenson, J. S. Landefeld, and P. Schreyer, eds. Measuring Economic Sustainability and Progress, Studies in Income and Wealth, volume 72, Chicago, University of Chicago Press, NBER, pp. 461-491, 2014.

Colby, S. L. and J. M. Ortman,“The Baby Boom Cohort in the United States: 2012 to 2060,” Current Population Reports, Population Estimates and Projections, P25-1141, May 2014.

Coremberg, A., “The Economic Value of Human Capital and Education in an Unstable Economy: the Case of Argentina,” paper prepared for the 31st General Conference of the International Association for Research in Income and Wealth, St. Gallen, Switzerland, August 22-28, 2010.

Fraumeni, B., "Human Capital and Investment in Education: A Streamlined Approach” presentation at a Fondazione Giovanni Agnelli/OE CD workshop on human capital accounts, Turin, Italy, November 3, available at http://www.powershow.com/view/132efc-OTZlY / Barbara_M_Fraumeni_flash_ppt_presentation, 2008a.

Fraumeni, B. M., “Human Capital: From Indicators to Accounts,” paper presented at a Fondazione Giovanni Agnelli/OECD workshop on human capital accounts, Turin, Italy, November 4, 2008b. 
Fraumeni, B.M. and G. Liu, "Human Capital: Country Estimates Using Alternative Approaches," chapter 4 in UNU-IHDP and UNEP (2014). Inclusive Wealth Report 2014, Measuring Progress Toward Sustainability, Cambridge: Cambridge University Press, pp. 109122, 2014.

Gundimeda, H., S. Sanyal, R. Sinha, and P. Sukhdev, "Estimating the Value of Educational Capital Formation in India,” Monograph 5, GAISP (Green Accounting for Indian States Project), TERI Press, New Delhi, India, March, 2007.

Gu, W. and A. Wong, "Human Development and its Contribution to the Wealth Accounts in Canada," paper presented at the Canadian Economic Association Annual Conference, May 29, 2009.

Hotchkiss, J. and M. Shiferaw "Decomposing the Education Wage Gap: Everything but the Kitchen Sink,” Federal Reserve Bank of St. Louis Review, 93(4), pp. 243-71, July/August 2011.

Jorgenson, D. W., “Accounting for Capital,” in G. von Furstenberg, (ed.), Capital, Efficiency, and Growth, Cambridge, Ballinger, 1980, pp. 251-319, 1980.

Jorgenson, D. W., "Designing a New Architecture for the U.S. National Accounts." The Annals of the American Academy of Political and Social Science 631, no. 1, pp. 63-74, 2010.

Jorgenson, D. W. and B. M. Fraumeni, "The Accumulation of Human and Non-Human Capital, 1948-1984," in R. Lipsey and H. Tice eds., The Measurement of Saving, Investment and Wealth, Chicago, University of Chicago Press, NBER, pp. 227-282, 1989.

—_, "Investment in Education and U.S. Economic Growth," Scandinavian Journal of Economics, Vol. 94, supplement, pp. S51-70, 1992a.

—_, "The Output of the Education Sector," in Z. Griliches, T. Breshnahan, M. Manser, and E. Berndt eds., The Output of the Service Sector, Chicago, NBER, pp. 303-341, $1992 \mathrm{~b}$.

Jorgenson, D.W., M. S. Ho, and J.D. Samuels, J.D., "What will revive U.S. Economic Growth? Lessons from a Prototype Industry-Level Production Account for the United States," Journal of Policy Modeling, Volume 34, No 4, July-August, pp. 674-691, 2014.

Jorgenson, D. W. and J. S. Landefeld, "Blueprint for Expanded and Integrated U.S. Accounts: Review, Assessment, and Next Steps,” in D. W. Jorgenson, J. S. Landefeld, and W. D. Nordhaus, eds. A New Architecture for the U.S. National Accounts, Chicago, University of Chicago Press, NBER, pp. 13-112, 2006.

Jorgenson, D. W., and J. S. Landefeld, "Implementation of a New Architecture for the U.S. National Accounts," American Economic Review, Papers and Proceedings, volume 99, number 2, May, pp. 64-68, 2009. 
Le, T. V. T., J. Gibson, and L. Oxley, "Measuring the Stock of Human Capital in New Zealand,” Mathematics and Computers in Simulation, Volume 68, Issue 5-6, May, pp. 485-98, 2005.

Li, H., B. Fraumeni, Z. Liu, and X. Wang, "Human Capital in China,” China Center for Human Capital and Labor Market Research, Central University of Finance and Economics, Beijing, China, October 6, 2009, Prepared for the International Symposium on Measuring Human Capital and Its Impact on Welfare and Growth: Inaugurating the China Human Capital Index, in English and Chinese, Beijing, China, October 9-10, 2009a.

—, "Human Capital in China,” National Bureau of Economic Research Working Paper \#1500, November, 2009b.

Li, H., Y. Liang, B. Fraumeni, Z. Liu, and X.Wang, “China’s Human Capital Measurement and Index Construction,” Economic Research Journal, in Chinese, August, pp. 42-54, 2010a.

Li, H., Principal Investigator, "Human Capital in China,” China Center for Human Capital and Labor Market Research, Central University of Finance and Economics, Beijing, China, October, 2010b.

_- "Human Capital in China," China Center for Human Capital and Labor Market Research, Central University of Finance and Economics, Beijing, China, October, 2011.

— , "Human Capital in China," China Center for Human Capital and Labor Market Research, Central University of Finance and Economics, Beijing, China, December, 2012.

_- "Human Capital in China,” China Center for Human Capital and Labor Market Research, Central University of Finance and Economics, Beijing, China, December, 2013.

_ - "Human Capital in China," China Center for Human Capital and Labor Market Research, Central University of Finance and Economics, Beijing, China, October, 2014.

Li, H., Y. Liang, B. Fraumeni, Z. Liu, and X.Wang, "Human Capital in China,1985-2008,” Review of Income and Wealth, series 59, number 2, June, pp. 212-234, 2013.

Li, H. Q. Liu, B. Li, B. Fraumeni and X. Zhang, "Human Capital Estimates in China: New Panel Data 1985-2010,” in China Economic Review, with Haizheng Li, Qinyi Liu, Bo Li, and Xiaobei Zhang, volume 30, issue C, 2014, pp. 397-418, 2014.

Liu, G. and M. Greaker, "Measuring the Stock of Human Capital for Norway - A Lifetime Labour Income Approach,” Documents, 2009/12, Statistics Norway, 2009. 
Liu, G., "Measuring the Stock of Human Capital for International and Intertemporal Comparisons," in D. W. Jorgenson, J. S. Landefeld, and P. Schreyer, eds. Measuring Economic Sustainability and Progress, Studies in Income and Wealth, volume 72, Chicago, University of Chicago Press, NBER, pp. 493-544, 2014.

—. "Measuring the Stock of Human Capital for Comparative Analysis: An Application of the Lifetime Income Approach to Selected Countries," OECD Statistics Directorate, Working Paper \#41, STD/DOC(2011)6, October 10, 2011.

OECD, Measuring Student Knowledge and Skills: A New Framework for Assessment, OECD Programme for International Student Assessment, OECD Publishing, 1999.

, PIAAC website, http://www.oecd.org/site/piaac/, undated.

, PISA website, http://www.oecd.org/pisa/pisaproducts/, undated.

, PISA 2006: Science Competencies for Tomorrow's World Executive Summary, OECD Publishing, 2007.

, OECD Skills Outlook 2013: First Results from the Survey of Adult Skills, OECD Publishing, November 2013, http://dx.doi.org/10.1787/9789264204256-en.

, Skilled for Life? Key Findings from the Survey of Adult Skills, OECD Publishing, 2013.

, The PISA 2003 Assessment Framework - Mathematics, Reading, Science, and Problem Solving Knowledge and Skills, Programme for International Student Assessment, OECD Publishing, 2003.

, Statistics Directorate, Committee on Statistics, Approaches to Measuring the Stock of Human Capital: A Review of Country Practices, prepared by R. Boarini and M. Mira d'Ercole with contributions by G. Liu, OECD Working Paper \#48, STD/DOC(2012)4, November 23 ${ }^{\text {rd }}$, 2012.

OECD, Statistics Directorate, Committee on Statistics, The OECD Human Capital Project: Progress Report, STD/CSTST/RD(2010)3, Meeting of the Committee on Statistics, June 7-8, OECD Conference Centre, OECD Headquarters, Paris, May, 2010.

O‘Mahony, M. and P.A. Stevens, "International Comparisons of Performance in the Provision of Public Services: Outcome Based Measures for Education,” National Institute of Economic and Social Research, London, U.K., 2004.

Statistics Norway, "How to Take the UNECE Task Force on Measuring Human Capital Forward? A Note for Discussion,” January, 2014. 
Stiglitz, J.E., A. Sen and J.-P. Fitoussi, Report by the Commission on the Measurement of Economic Performance and Social Progress, http://www.stiglitz-sen-fitoussi.fr/documents/rapport_anglais.pdf, 2009.

UNU-IHDP and UNEP. Inclusive Wealth Report 2014. Measuring Progress Toward Sustainability. Cambridge: Cambridge University Press, 2014.

U.S. Census Bureau, “Historical National Population Estimates: July 1, 1948 to July 1, 1999,” Population Estimates Program, Population Division, Internet Release Date: April 11, 2000, Revised date: June 28, 2000, https://www.census.gov/population/estimates/nation/popclockest.txt .

Wei, H., "Developments in the Estimation of the Value of Human Capital in Australia," paper presented at the Fondazione Giovanni Agnelli/OECD Workshop on the Measurement of Human Capital, Turin, Italy, November 3, 2008 a.

— - "Measuring Australia's Human Capital Development: The Role of Post-School Education and the Impact of Population Ageing," Statistical Journal of the IAO, S 24, pp. 183-191, 2007.

, "Measuring Human Capital and Its Applications for Australia," a thesis submitted for the degree of doctor of philosophy of the University of Canberra, 2008b.

World Bank, “Data, GDP (constant 2005 US\$)," accessed in May 2015 at http://data.worldbank.org/indicator/NY.GDP.MKTP.KD

, “Data, GDP (current LCU),” accessed in May 2015 at

http://data.worldbank.org/indicator/NY.GDP.MKTP.CN

, The Changing Wealth of Nations-- Measuring Sustainable Development in the New Millennium, The World Bank, Washington, DC, 2011.

Where is the Wealth of Nations, Measuring Capital for the 21 $2{ }^{\text {st }}$ Century, The International Bank for Reconstruction and Development/The World Bank, Washington, DC, 2006. 